\title{
The Development of Epoxy Foam Resin Grinding Wheel
}

\author{
Jiaoli Liang, Shuiyuan Shao \\ College of Materials Science and Engineering,Xi'an University of Science and Technology,Xi'an \\ 710054, China
}

\begin{abstract}
Keyword: Modified silicon carbide, Foam Epoxy, Grinding Wheel
Abstract: In this study,grafting modification silicon carbide powders were manufactured successfully by KH-550 and acrylamide monomer in nitrogen atmosphere, and the modified silicon carbide epoxy foam resin grinding wheels were prepared by mixing epoxy resin with silicon carbides. The structure of the modified silicon carbide was characterized by using scanning electron microscopy(SEM) and laser particle size distribution analyzer.The cross section morphology of the resin grinding wheels with different types of blowing agents were observed by optical microscope. Besides, the mechanical properties, life-span and grinding performance of resin grinding wheel were systematically analyzed and studied with different dosage of blowing agent. The results were shown that mechanical properties were related to greatly the blowing agent content. The life-span and grinding performance both initially increased with blowing agent, but begin to decrease after exceeding a certain value.Their maximum values were obtained when 8-wt\% OBSH blowing agent,the life-span is $89 \mathrm{~h}$, the grinding ratio is 70.20 and abrasion rate is 0.00025 .
\end{abstract}

\section{Introduction}

Recently resin grinding wheels, as one kind of the tools of industrial production, have played an important role in many fields such as metal, nonmetal material cutting, grinding ${ }^{[1]}$. Resin grinding wheels were fabricated using adhesive and abrasive.The production cycle of the resin grinding wheel is short, the preparation technology is simple and it is easily to operate. The properties of resin grinding wheels such as considerable polishing performance, high the grinding rate, better elasticity and small damage on the surface of a work piece make them be used widely ${ }^{[2]}$. In the past, abundant researchers were carried out to manufacture resin grinding wheels, However, only a few of studies were related to fabricate foam resin ${ }^{[3]}$ grinding wheels. Foam resin grinding wheels have low density, high heat dissipation performance, the characteristics of light weight as compared to resin grinding wheels. They have been shown to be a potential market in a number of grinding wheels.

Previous studies have shown that polyvinyl alcohol foam resin grinding wheels can be used in metal, nonmetal material cutting, grinding. However, due to polyvinyl alcohol, formaldehyde and abrasive were used as the main raw material ${ }^{[4]}$ in polyvinyl alcohol resin grinding wheels, they tend to suffer from issues of high toxicity, low strength,and high processing costs. In order to overcome these drawbacks, the epoxy foam resin grinding wheel were prepared in this study.It is well known that epoxy resins have been shown excellent comprehensive performance ${ }^{[5]}$, so epoxy resin were regarded as binder .For the abrasive, silicon carbide was selected for its outstanding wear resistance, thermal conductivity and thermal stability ${ }^{[6]}$.

The major purpose of this research was to fabricate the epoxy foam resin grinding wheel using grafting modification method ${ }^{[7]}$ to improve the compatibility of abrasive and adhesive, and to study the modification effect of silicon carbide and performances of foam resin grinding wheel.

\section{Experimental}

\subsection{Raw materials}

Silicon carbide powders an average diameter of 10um and an irregular polyhedral shape were obtained from Dongguan game step Katherine Heng abrasive material. Ammonium ceric nitrate with AR, purchased from Nanjing chemical reagent Co., Ltd was used as initiator in the present study. Acrylamide sourced from Shen Hao Shanghai chemical reagent Co .was monomer. The adhesive used was a bisphenol-A epoxy resin (E-51) combined with a curing 
agent (diethylenetriamine), both of which were supplied by Shanghai wild chemical co.The resin and curing agent were mixed at a weight ratio of 5:2, and then combined with blowing agents $\mathrm{OBSH}$, solvent toluene, coupling agent $\mathrm{KH}-550$, diluent, mold release agents .etc. to produce foam resin grinding wheel.

\subsection{Silicon carbide pretreatment}

The silicon carbide powders were dried at $110{ }^{\circ} \mathrm{C}$ after washed with distilled water. silicon carbide powders dried and the solvent toluene with a certain proportion were poured into a $500 \mathrm{ml}$ four-necked flask, in which have been installed a thermometer, reflux condenser tube,and nitrogen gas tube. 10min after the coupling agent KH-550 were added in four-necked flask. Silicon carbide powders were designed under flowing nitrogen at $95{ }^{\circ} \mathrm{C}$ for $5 \mathrm{~h}$ (the whole process of maintaining the anhydrous state), after the completion of the reaction, silicon carbide powders were filtered, were washed with distilled water, dried at under $100{ }^{\circ} \mathrm{C}$.

\subsection{Silicon carbide grafting modification}

The silicon carbide pretreatment powders and dissolving a certain mass ratio of acrylamide $300 \mathrm{ml}$ of distilled water were added into a $500 \mathrm{ml}$ four-necked flask, equipped with a thermometer, a reflux condenser tube, a mechanical stirrer and a nitrogen airway, Cerium ammonium nitrate was mixed with $0.25 \mathrm{~g}$ after stiring a period of time. The reactants were heated to $30{ }^{\circ} \mathrm{C}$ for $3 \mathrm{~h}$, the products were filtered, washed, dried under vacuum at $80^{\circ} \mathrm{C}$ for $12 \mathrm{~h}$.

\subsection{Preparation of foam resin grinding wheel}

Bisphenol A epoxy resin E-51, and diluent was added to a 250ml tetrafluoroethylene three-necked flask, silicon carbide powders of graft-modified were slowly added to tetrafluoroethylene three-necked flask at $60{ }^{\circ} \mathrm{C}$ in a water bath .and finally curing agents were added slowly and stirred well.The composites samples were subsequently transferred to a mold, pressed foaming at $150{ }^{\circ} \mathrm{C}$ for $2 \mathrm{~min}$, then elevated temperature for curing reaction, and then cooled to room temperature. The epoxy foam resin was prepared.

\subsection{Experimental techniques}

The detailed morphology of the modified silicon carbide were investigated by using field-emission scanning electron microscopy (FE-SEM, operated at 5 - $10 \mathrm{kV}$,Quanta 3D). The laser particle size distribution analyzer data were recorded on a HYL -1076 laser particle size distribution analyzer. volume percentage was used and the particle size range was set from 0.1to $1000 \mathrm{um}$.

The cell morphology of foam grinding wheel were observed using a BM-53XBC metallographic microscope. The tensile testing were conducted using a universal testing machine(UTS, Taewon Tech., MTS-810) at a 5-mm/min speed with in order to determine the individual mechanical properties of the foam resin grinding wheel. The tear strength and hardness were detected in accordance with the respective standard. Grinding performance tests were performed with a abrasion machine at a $2500 \mathrm{r} / \mathrm{min}$ speed .

\section{Results and Discussion}

\subsection{Silicon carbide characterization}

The structures of the raw silicon carbide and modified silicon carbide observed by scanning electron microscopy (SEM) are shown in Fig.1. From this SEM (a)observations it is evident that majority of the raw silicon carbide particles are nearly angular shape and present state of reunion in nature.The surface of raw silicon carbide is shape. It can be seen from Fig.1(b)that the pretreatment silicon carbide particles with KH-550 were spherical shape,The Surface of pretreatment silicon carbide is rounded without protruding edges and corners.A layer of organic single molecule membrane on the surface of grafting modification of silicon carbide with acrylamide can be clearly detected in Fig.1(c), the sphericity of surface is relatively high,and the dispersion state of silicon carbide particles were showed ${ }^{[8]}$. 


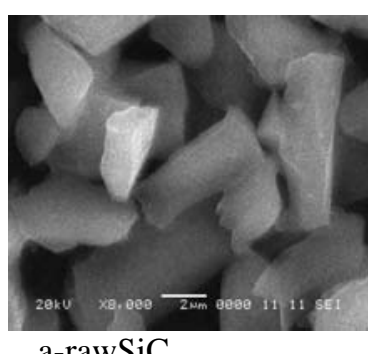

a-rawSiC

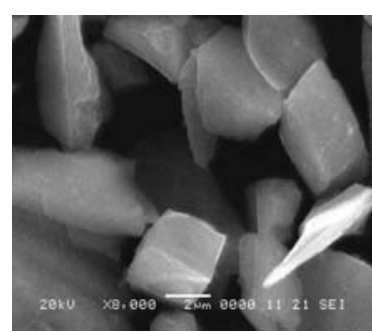

b-KH-550 pretreatment SiC

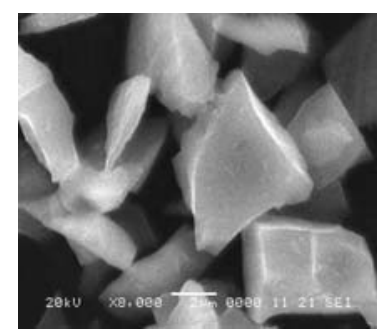

c- acrylamide grafting $\mathrm{SiC}$

Fig.1 SEMs of SiC powders before and after modification

The particle size distribution of uncoated and coated silicon carbide powders were displayed in Fig.2.Compared to the image of particle size of uncoated silicon carbide powders in Fig.2(a),the particles diameter of coated silicon carbide powders(Figs.2(b) and (c)) were larger. From Fig. 2. it can be see that the average size of the particles silicon carbide was increased from 10.58um to 13.10 um and then 13.78um, d10 and d90 were increased correspondingly, indicating that $\mathrm{KH}-550$ was effectively coated on the surface of the silicon carbide, acrylamide was successfully grafted onto KH-550 above. The modification effect of silicon carbide powders can be seen evidently, so dispersibility of silicon carbide particles were improved in the epoxy. For this reason is that organic single molecule membrane on the surface of grafting modification of silicon carbide with acrylamide can prevent or weaken reunion of silicon carbide particles, and organic produce steric repulsion ${ }^{[9]}$.

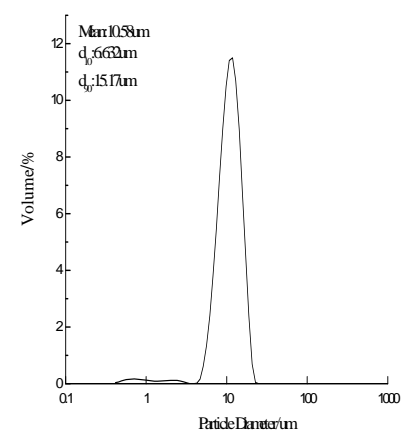

a-raw $\mathrm{SiC}$

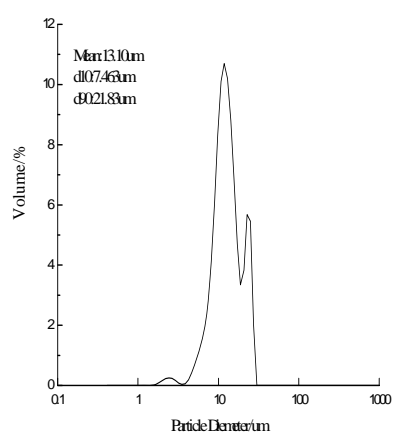

b-KH-550 pretreatment SiC

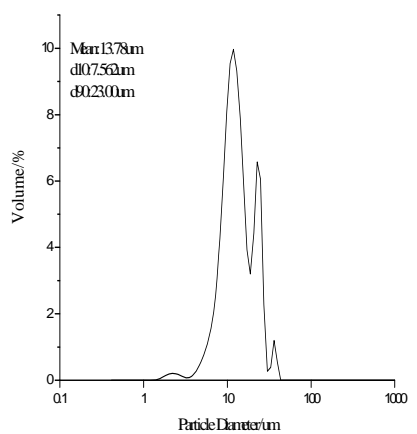

c- acrylamide grafting $\mathrm{SiC}$

Fig.2 Particle size distribution of uncoated and coated SiC powder

\subsection{Foam grinding wheel characterization}

Fig.3.shows the section morphology of the grinding wheels with with different types of blowing agents. As we can see from image(a ),the cell size in AC foaming grinding wheel was large, which easily absorb water and make the matrix swelling and become soft. Moreover, it can be seen that adjacent ligaments ${ }^{[10]}$ were so thin that difficult to bear the load when the grinding wheels were putting pressure on. From Fig.3(b)it was observed clearly that the cell size were not homogeneous and adjacent ligaments were thick, which may be not lead to the diffusion of heat generated while the grinding in time. In Fig.3(c),obviously, the cell density ${ }^{[11]}$ was moderate, and the cell size were uniform $\mathrm{OBSH}^{[12]}$ in foaming grinding wheel.The above two conditions are advantageous to heat diffusion of grinding wheel. 


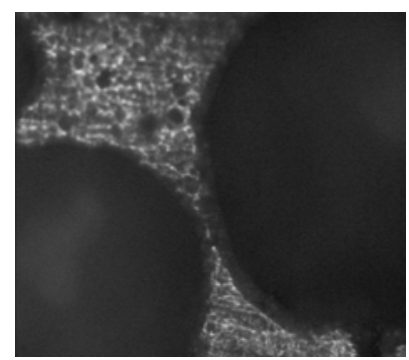

$\mathrm{a}-\mathrm{AC}$

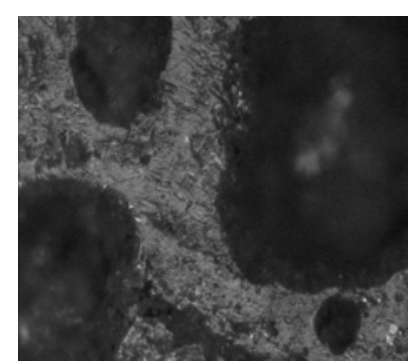

b-H

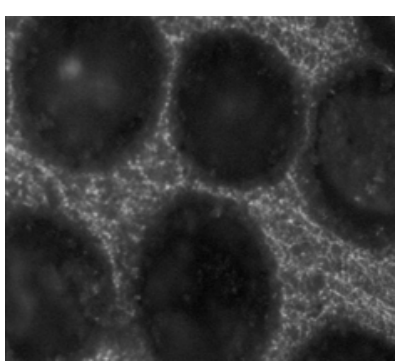

c-OBSH

Fig.3The section morphology of the grinding wheels produced with different types of foaming agents

Grinding wheels have to have certain mechanical properties ${ }^{[13]}$ in order to meet the metal, nonmetal polishing, cutting. Measured values of the the tensile strength, tear strength and hardness of epoxy foam resin grinding wheel with various resin contents are shown in Table 1.The mechanical properties of epoxy foam resin grinding wheel are significantly related to their resin content; an increase in the resin content causes a corresponding increase in the mechanical properties. However, increase of in the mechanical properties was observed only for the tensile strength and tear strength. Result showed that epoxy resin contributed to tensile strength and tear strength as compared to silicon carbide with resin content increasing. From this it can be seen that the hardness initially increase with resin contents, but begin to decrease after exceeding a certain value, the maximum value of hardness is obtained for $35 \%$. The main reason is attribute to hardness of silicon carbide higher than the epoxy resin.The hardness of resin grinding wheel tremendously depended on silicon carbide in low ration .Nevertheless, following the increase in the ration of epoxy resin to silicon carbide. it greatly depends on the resin when resin contents are more than $35 \%$, therefore, hardness performance of resin grinding wheel were declining.

Table 1 Effect of resin content on the mechanical properties

\begin{tabular}{ccccc}
\hline Sample & $\begin{array}{c}\text { Resin } \\
\text { content } \\
(\%)\end{array}$ & $\begin{array}{c}\text { Tensile } \\
\text { strength } \\
(\mathrm{M} \text { pa) }\end{array}$ & $\begin{array}{c}\text { Tear } \\
\text { strength } \\
(\mathrm{KN} / \mathrm{m})\end{array}$ & $\begin{array}{c}\text { Hardness } \\
\text { (Shore A) }\end{array}$ \\
\hline 1 & 15 & 20.1 & 50.2 & 90 \\
2 & 25 & 23.5 & 53.1 & 93 \\
3 & 35 & 25.8 & 54.3 & 95 \\
4 & 45 & 28.6 & 56.2 & 92 \\
5 & 55 & 29.8 & 48.5 & 89 \\
\hline
\end{tabular}

It is well known that a lot of heat can be produced when the resin grinding wheel polishing under high pressure and high temperature. Sometimes, temperature of the resin grinding wheel was increased sharply in a short period of time and surpassed the use of resin temperature. It is necessary to cool the grinding wheel with cooling water while polishing. Therefore, resin grinding wheel were needed to meet certain mechanical properties in the humid environment. Table 2 summarizes the results for the effect of wet environment on the mechanical properties. By soaking sample in water for $24 \mathrm{~h}$ water absorption 0.41was obtained, and the mechanical properties were carried out after the sample soaked. The values of mechanical strength had virtually a slightly lower than dry due to absorbing water. Nonetheless,the resin grinding wheel still able to meet mechanical properties in the humid environment. These test results illustrated resin grinding wheel can be employed in wet environment.

Table 2 Effect of wet environment on the mechanical properties

\begin{tabular}{ccccc}
\hline Sample & $\begin{array}{c}\text { water } \\
\text { absorption } \\
(\%)\end{array}$ & $\begin{array}{c}\text { Tensile } \\
\text { strength } \\
(\mathrm{M} \text { pa })\end{array}$ & $\begin{array}{c}\text { Tear } \\
\text { strength } \\
(\mathrm{KN} / \mathrm{m})\end{array}$ & $\begin{array}{c}\text { Hardness } \\
\text { (Shore A) }\end{array}$ \\
\hline 0 & $/$ & 25.8 & 54.3 & 95 \\
1 & 0.41 & 24.7 & 52.5 & 91 \\
\hline
\end{tabular}

Note: 0 and 1 respectively before and after soaked samples 
The influences of cell rate on life-span of resin grinding wheel were also evaluated. Table 3 displayed the outcome for the effect of OBSH blowing agent content on life-span of resin grinding wheel.It can be seen that cell rate had an impact on the life-span of resin grinding wheel as indicated in Table 3. As mentioned above in Fig.3, the life-span initially increase with a fixed value of cell rate.It is due to the suitable cell rate play absorption of heat, heat dissipation, and vibration reduction roles ${ }^{[14]}$, so the life-span can be prolonged. The heat generated by grinding action not be diffused timely because of low cell density and cell rate with small blowing agent contents. Temperature of resin grinding wheel by heat can not be diffused caused rising sharply are likely to exceed temperature of resin were used. The life-span of resin grinding wheel may be decreased due to high temperature. The cell can absorb a lot of cooling water and give rise to epoxy matrix swell and become soft when cell density was high or cell rate was excessive with the an increasing in blowing agent.This result can be lead to not only mechanical performance of resin grinding wheel degradation but also life-span of resin grinding wheel shorten.

Table 3 The influence of blowing agent content on the life-span

\begin{tabular}{ccc}
\hline Sample & Blowing agent $\mathrm{t}(\%)$ & Life-span $/ \mathrm{h}$ \\
\hline 1 & 2 & 75 \\
2 & 4 & 78 \\
3 & 6 & 85 \\
4 & 8 & 89 \\
5 & 10 & 79 \\
\hline
\end{tabular}

For the resin grinding wheel, grinding performance is one of the most important performance. The grinding performance were examined by a abrasion machine at a $2500 \mathrm{r} / \mathrm{min}$ speed. The grinding performance of resin grinding wheel with different blowing agent contents were exhibited in Table 4. It was observed that when the mass fraction of OBSH was $8 \%$, the grinding ratio ${ }^{[15]}$ and abrasion rate achieved the best, The grinding ratio is 70.20 and abrasion rate is 0.00025 . Meanwhile, its grinding performance was weaker than that in low ratio. The reason for this was that cell size cell density, and cell struts or cell walls ${ }^{[16]}$ were different with an increase in blowing agent. When the blowing agent content was increased from 2-wt.\% to 8wt.\%, the amount of grinding wheel wear increased from 0.6 to $0.9 \mathrm{~g}$, and the grinding wheel abrasion rate increased also from 0.00030 to 0.00045 . Nonetheless, the amount of grinding wheel abrasion and the grinding wheel abrasion rate both presented minimum value with 8 -wt.\% OBSH blowing agent.Sample with 10 -wt.\% blowing agent had the highest value in that than any of resin grinding wheel with blowing agent content. The results demonstrated that the blowing agent had an significant impact on cell size distribution and cell density. Scarce number of cells and low-density cell in a low content of blowing agent had negative effects on making temperature of grinding wheel low while polishing and grinding. The grinding wheel was damaged by high temperature, which may be cause grinding performance degradation. Nevertheless, the a high blowing agent content also show bad influence on grinding performance. The fact was interpreted as the weak of cell struts and cell wall unable to bear load and the resin grinding wheel was destroyed when pressure is applied to the grinding wheel. A large number of grinding heat was spread by the cell size homogeneous distribution and suitable cell density. Meanwhile, moderate the cell struts and cell walls had the ability to withstand mechanical strength.Thus, grinding performance was the best when the blowing agent was 8-wt \%.

Table 4 The influence of blowing agent content on grinding performance

\begin{tabular}{cccccc}
$\begin{array}{c}\text { Blowing agent } \\
\text { content } \\
\%\end{array}$ & $\begin{array}{c}\text { Grinding } \\
\text { wheel abrasion } \\
\Delta \mathrm{m} 1 / \mathrm{g}\end{array}$ & $\begin{array}{c}\text { Steel } \\
\text { abrasion } \\
\triangle \mathrm{m} 2 / \mathrm{g}\end{array}$ & $\begin{array}{c}\text { grinding } \\
\text { ratio } \\
\triangle \mathrm{m} 2 / \triangle \mathrm{m} 1\end{array}$ & $\begin{array}{c}\text { Grinding } \\
\text { efficiency } \\
\triangle \mathrm{m} 2 / \mathrm{t}\end{array}$ & $\begin{array}{c}\text { grinding wheel } \\
\text { abrasion rate } \triangle \\
\mathrm{m} 1 / \mathrm{t}\end{array}$ \\
& & & & & \\
\hline 2 & 0.6 & 35.6 & 59.33 & 0.018 & 0.00030 \\
4 & 0.7 & 36.4 & 52.00 & 0.018 & 0.00035 \\
6 & 0.9 & 35.3 & 39.22 & 0.018 & 0.00045 \\
8 & 0.5 & 35.1 & 70.20 & 0.018 & 0.00025 \\
10 & 1.0 & 33.2 & 33.20 & 0.017 & 0.00050 \\
\hline
\end{tabular}




\section{Conclusion}

In summary, we have successfully graft modification of silicon carbide by KH-550 and acrylamide monomer in nitrogen atmosphere,and the modified silicon carbide epoxy foam resin grinding wheels were prepared by mixing epoxy resin with silicon carbides. Laser particle size distribution analyzer and scanning electron microscopy have established the detailed morphology and particle size of the modified silicon carbide material. The measured results indicates that a chemical bonding formed between silicon carbide and acrylamide monomer, and a layer of organic single molecule membrane formed on the surface of silicon carbide.In addition,the section morphology, mechanical properties, life-span and grinding performance of foam resin grinding wheel were researched with blowing agent.The statistical results showed that types of blowing agent and blowing agent content played important roles in various performance of foam resin grinding wheel. The grinding wheel was displayed the cell size homogeneous distribution, suitable cell density while keeping cell shapes by using OBSH blowing agent as compared to AC or H blowing agent. Mechanical tests showed that both tensile strength and tear strength of resin grinding wheel increased with blowing agent, but hardness decreased with excessive addition of blowing agent. From analysis of life-span and grinding performance, it was clear that both initially increase with blowing agent, but begin to decrease after exceeding a certain value. The maximum values of life-span and and grinding performance were obtained for $8-w t \%$, the life-span is $89 \mathrm{~h}$, the grinding ratio is 70.20 and abrasion rate is 0.00025 .

\section{References}

[1]Wang W, Su X Q, Liu Y. The development of the new type of $300 \mathrm{t}$ resin grinding wheel machine[J]. Diamond \& Abrasives Engineering,2015,3(35):71-75

[2]Li D K, Yan F Y, Huang H Q. SiC base resin abrasive brush materials preparation and performance[J]. Plastic, 2014,43(2):15-17

[3]Liu Q, Li S, Gong L C. The development and application of foam structure[J]. Plastics Science and Technolog, 2009,37(8):50-55

[4]Gao F Y, Yue C J. PVA wheel polishing performance[J]. Abrasives and Grinding, 1992,6(72):19-21

[5]Kim J, Kim Y D , Nam D G, Bam J S, Yeum J H. Thermal Properties of Epoxy Composites with Silicon Carbide and/or Graphite[J]. Journal of the Korean Physical Society,2016,4(68): 551-556

[6]Ting T H, Chiang C C, Cheng K F, Hong Y S. Effect of silicon carbide dispersion on the microwave absorbing properties of silicon carbide-epoxy composites in 2-40 GHz[J]. J Polym Res (2016) 23: 82

[7] Gu J W, Zhang Q Y, Dang J, Zhang J P, Chen S J. Preparation and mechanical properties researches of silane coupling reagent modified b-silicon carbide filled epoxy composites[J]. Polym. Bull. (2009) 62:689-697

[8]Hua Y, Li Y P, Jiang D G, Wang H, Wu G C. The surface modification of silicon carbide in glass edge grinding of diamond polishing wheel (UPR) $[\mathrm{J}]$. Diamond \& Abrasives Engineering, 2005,149(5):32-35

[9]Li A Y, Xu G C,Xing H L. Nano powder surface modification and application[J]. New Chemical Materials, 2002,10(30):25-28

[10]Wang $X$. The preparation and the structure of the phenolic resin matrix carbon foam control[D].ShangHai: Tongji University Department of Chemistry, 2007:21- 26.

[11]Lee S, Hong I K. Microcellular foaming of silicone rubber with supercritical carbon dioxide[J].Korean J.Chem.Eng.2014,31(1):166-171

[12]Chen H, Zhao J Z, Liu J. Status and Prospect of foam blowing agent[J]. Plastics Science and Technolog, 2009,37,(2):68-72

[13]Nayak S S, Patnaik T K. Development of Silicon Carbide Reinforced Jute Epoxy

Composites: Physical, Mechanical and Thermo-mechanical Characterizations[J] Silicon,2016,4,12

[14]Du J C. Microporous polyurethane polishing abrasive[J]. Chemical Propellants \& Polymeric 
Materials, 2004,2(3):36-38

[15]Chen L,Zeng L M,Ye X C, Zhang C, Song Y X. Resin grinding wheel coupling on the performance of the diamond[J]. Diamond \& Abrasives Engineering,2010,30(4):55-57

[16]Konar S, Sain M,Gu R J. Development and characterization of flexible epoxy foam with reactive liquid rubber and starch[J].J Mater Sci,2014,49:3125-3134 